\title{
Triterpenoid Saponins from the Stem Bark of Acanthopanax brachypus HARMS
}

\author{
Hao-Bin Hu, * Xu-Dong Zheng, Hong CAo, Xiao-Qiang Guo, and Huai-Sheng Hu \\ College of Chemistry and Chemical Engineering, Longdong University; South Street 137, Xifeng District, Qingyang City, \\ 745000, Gansu Province, China. Received March 19, 2009; accepted May 7, 2009; published online June 18, 2009
}

Two new triterpenoid saponins, brachyposide A (1) $\{3-O-\beta$-D-galactopyranosyl- $(1 \rightarrow 2)-[\beta$-D-xylopyranosyl$(1 \rightarrow 3)]-\beta$-D-glucuronopyranosyl-2 $\beta, 3 \beta, 16 \alpha, 23$-tetrahydroxyolean-12-en-28-oic acid 28 - $O$ - $\beta$-D-apiofuranosyl-(1 $\rightarrow$ $3)-\beta$-D-xylopyranosyl-(1 $\rightarrow 4)$ - $\alpha$-L-rhamnopyranosyl-(1 $\rightarrow 2)$ - $\alpha$-L-arabinopyranosyl ester $\}$ and brachyposide $B(2)$ $\{3-O$ - $\beta$-D-glucopyranosyl-(1 $\rightarrow 3)$ - $\beta$-D-galactopyranosyl- $(1 \rightarrow 3)$ - $\beta$-D-glucuronopyranosyl-2 $\beta, 3 \beta, 23$-trihydroxyolean12-en-28-oic acid 28- $O$ - $\beta$-D-xylopyranosyl-( $1 \rightarrow 4)$-[ $\beta$-D-apiofuranosyl-( $\rightarrow 3)]$ - $\alpha$-L-rhamnopyranosyl-( $1 \rightarrow 2)-\beta$-Dglucopyranosyl ester\}, together with four known triterpenoid saponins, including tabguticoside $A$, nipponoside D, palmatoside $\mathbf{E}$ and ciwujianoside $\mathrm{A}_{1}$, were isolated from the stem bark of Acanthopanax brachypus. Their structures were elucidated on the basis of spectroscopic and chemical evidence.

Key words Acanthopanax brachypus; Araliaceae; triterpenoid saponin; brachyposide A; brachyposide B

The Acanthopanax genus belonging to the Araliaceae family includes 37 species around the world, which are widely distributed in the northeast of Asia. Of these, 26 species and 18 varieties grow in mainland China, especially in the north. ${ }^{1,2)}$ The root and stem bark of these plants have been clinically used for a long time as a tonic and sedative, as well as for the treatment of rheumatism, diabetes, chronic bronchitis, hypertension, anti-stress and ischemic heart disease, and gastric ulcer. ${ }^{3)}$ Previous phytochemical studies on Acanthopanax species established the presence of triterpenoid saponins. ${ }^{4-6)}$

An endangered shrub in the wild due to overharvesting and loss of habitat through deforestation, Acanthopanax brachypus HARMS is distributed in a narrow geographical area, most in the loess plateau of the northwest of China. ${ }^{7}$ Nowadays, the parts of this plant such as the roots, leaves and flowers are employed for various therapeutic purposes in China and Korea. ${ }^{8}$ However, to date, the research has mainly concentrated on the reproductive biology and ecology, and there have been few studies on the chemical composition and biological activity. Only syringaresinol diglucoside, syringin, sucrose, $\beta$-sitosterol and fatty acids have been previously isolated from this plant. ${ }^{9)}$ Further phytochemical investigation led to the isolation of two new triterpenoid saponins: brachy- posides A and B (1 and 2), along with tabguticoside A (3), ${ }^{10)}$ nipponoside D (4), ${ }^{11)}$ palmatoside $\mathrm{E}(\mathbf{5})^{12)}$ and ciwujianoside $\mathrm{A}_{1}(6)^{13)}$ from the stem bark of $A$. brachypus. Among these known compounds, compounds $\mathbf{3}$ and $\mathbf{5}$ were isolated for the first time from this species.

Compound 1 was obtained as a white amorphous powder, and gave positive Liebermann-Burchard and Molish reactions. The positive FAB-MS displayed a pseudo-molecular ion peak at $m / z 1539[\mathrm{M}+\mathrm{Na}]^{+}$. Combined with ${ }^{13} \mathrm{C}-\mathrm{NMR}$ data, its molecular formula was determined as $\mathrm{C}_{68} \mathrm{H}_{108} \mathrm{O}_{37}$ by (HR)-FAB-MS, $m / z \quad 1517.6621 \quad[\mathrm{M}+\mathrm{H}]^{+}$(Calcd for $\left.\mathrm{C}_{68} \mathrm{H}_{109} \mathrm{O}_{37}, 1517.6647\right)$. The IR spectrum exhibited absorptions at $3418 \mathrm{~cm}^{-1}(\mathrm{OH}), 1730 \mathrm{~cm}^{-1}$ (ester carbonyl), and $1648 \mathrm{~cm}^{-1}$ (double bond). The spectral features and physicochemical properties revealed $\mathbf{1}$ to be a triterpenoid saponin. The compound displayed 68 carbon signals in ${ }^{13} \mathrm{C}-\mathrm{NMR}$ spectrum and various distortionless enhancement by polarization transfer (DEPT) data, of which 30 were assigned to the aglycon and the remaining 45 to the sugar moieties (Table 1). The six $s p^{3}$ carbons at $\delta_{\mathrm{C}} 15.3,16.8,17.9,23.8$, 27.4 and 33.3 , and the two $s p^{2}$ carbons at $\delta_{\mathrm{C}} 123.0(\mathrm{CH})$ and 144.4 (C), coupled with information from the ${ }^{1} \mathrm{H}-\mathrm{NMR}$ ( angular methyl proton singlets at $\delta_{\mathrm{H}} 0.93,1.06,1.18,1.39$, 1.58 and 1.76 , and a broad triplet-like vinyl proton signal at

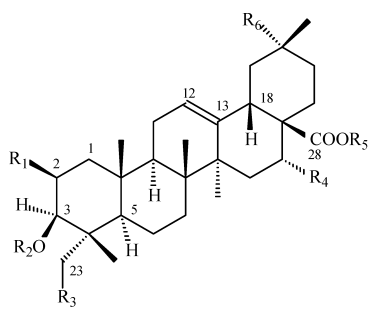

$\begin{array}{cll}\text { Saponin } & \mathrm{R}_{1} & \mathrm{R}_{2} \\ \mathbf{1} & \mathrm{OH} & \mathrm{GlcA}-[(3 \leftarrow 1)-\mathrm{Xyl}]-(2 \leftarrow 1)-\mathrm{Gal} \\ \mathbf{2} & \mathrm{OH} & \text { GlcA-}(3 \leftarrow 1)-\text { Gal- }(3 \leftarrow 1) \text {-Glc } \\ \mathbf{3} & \mathrm{H} & \mathrm{Glc} \\ \mathbf{4} & \mathrm{H} & \mathrm{H} \\ \mathbf{5} & \mathrm{H} & \text { Ara- }(2 \leftarrow 1)-\text { Rha- }(3 \leftarrow 1) \text {-Glc } \\ \mathbf{6} & \mathrm{H} & \text { Ara- }(2 \leftarrow 1)-\mathrm{Glc}\end{array}$

$\begin{array}{ll}\mathrm{R}_{3} & \mathrm{R}_{4} \\ \mathrm{OH} & \mathrm{OH} \\ \mathrm{OH} & \mathrm{H} \\ \mathrm{OH} & \mathrm{H} \\ \mathrm{OH} & \mathrm{H} \\ \mathrm{H} & \mathrm{OH} \\ \mathrm{H} & \mathrm{H}\end{array}$

Fig. 1. Structures of Isolated Triterpenoid Glycosides $\mathbf{1}-\mathbf{6}$ 
$\delta_{\mathrm{H}} 5.58$ (brs), indicated that the aglycon possessed an olean12-ene skeleton.

Furthermore, the hydroxymethyl $\left(\delta_{\mathrm{H}} 3.72,4.39\right.$ and $\delta_{\mathrm{C}}$ $65.8)$ and ester carbonyl $\left(\delta_{\mathrm{C}} 176.4\right)$ signals were assigned to C-23 and C-28 after an extensive 2D NMR study. Also, in the ${ }^{1} \mathrm{H}$ - and ${ }^{13} \mathrm{C}$-NMR spectra, three oxygenated methine carbon signals $\left(\delta_{\mathrm{C}} 70.5,83.7,74.2\right)$ were observed, the corresponding methine proton signals at $\delta_{\mathrm{H}} 4.81(\mathrm{brs}), 4.38(\mathrm{~d}$, $J=3.2 \mathrm{~Hz}$ ) and 5.16 (brs), suggesting the methine protons could be placed at $2 \alpha, 3 \alpha$ and $16 \beta$, respectively. Thus, the aglycon was identified as $2 \beta, 3 \beta, 16 \alpha, 23$-tetrahydroxyolean12-en-28-oic acid (polygalacic acid). ${ }^{14)}$ The chemical shifts of $\delta_{\mathrm{C}} 83.7(\mathrm{C}-3)$ and $176.4(\mathrm{C}-28)$ revealed that 1 was a 3,28bisdesmoside. On acid hydrolysis, 1 afforded D-glucuronic acid, D-galactose, D-xylose, L-arabinose, L-rhamnose and D-

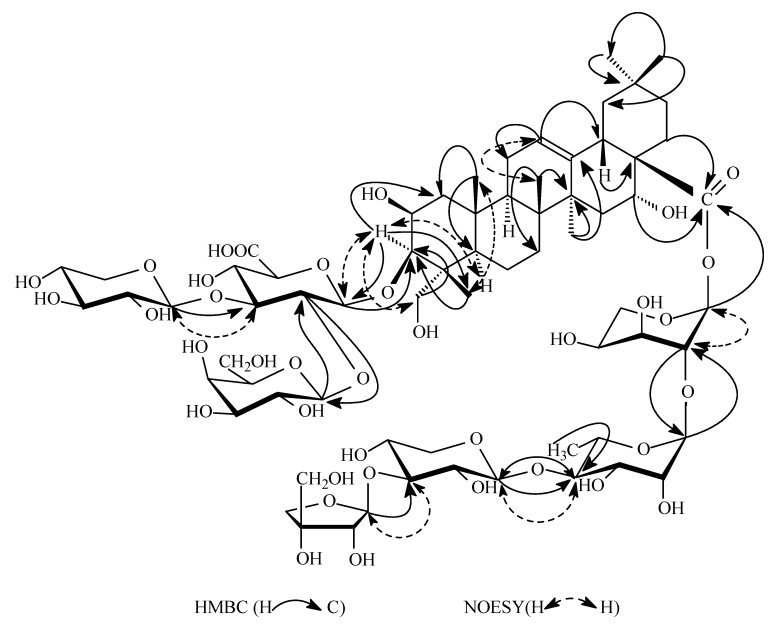

Fig. 2. Selected HMBC and NOESY Correlations of $\mathbf{1}$ apiose in the ratio of $1: 1: 2: 1: 1: 1$ as component sugars, which were identified by TLC and GC analysis after derivatization. ${ }^{15)}$ The ${ }^{1} \mathrm{H}$ - and ${ }^{13} \mathrm{C}-\mathrm{NMR}$ spectra also showed seven anomeric proton signals at $\delta_{\mathrm{H}} 6.36(\mathrm{~d}, J=2.8 \mathrm{~Hz}), 6.15(\mathrm{br} \mathrm{s})$, $6.05(\mathrm{~d}, J=4.8 \mathrm{~Hz}), 5.57$ (d, $J=7.6 \mathrm{~Hz}), 5.33$ (d, $J=7.5 \mathrm{~Hz})$, $5.18(\mathrm{~d}, J=7.8 \mathrm{~Hz})$ and $4.81(\mathrm{~d}, J=7.5 \mathrm{~Hz})$, as well as one methyl doublet at $\delta_{\mathrm{H}} 1.75(\mathrm{~d}, J=6.1 \mathrm{~Hz})$, and the corresponding carbon signals at $\delta_{\mathrm{C}} 93.8,101.4,111.6,105.8,106.2$, 106.7, 105.5 and 18.5, respectively. The assignments of all protons and carbon signals of the respective sugar components and the sequence of the oligosaccharide chain were determined by DEPT, ${ }^{1} \mathrm{H}-{ }^{1} \mathrm{H}$ chemical shift correlation specroscopy $\left({ }^{1} \mathrm{H}-{ }^{1} \mathrm{H}\right.$ COSY $),{ }^{1} \mathrm{H}$-detected heteronuclear multiple-bond correlation (HMBC) and nuclear Overhauser effect spectroscopy (NOESY) spectra of $\mathbf{1}$. The linkage of the sugar units at $\mathrm{C}-3$ of the aglycone was established from the following $\mathrm{HMBC}$ correlations: $\mathrm{H}-1\left(\delta_{\mathrm{H}} 5.57\right)$ of galactose with C-2 $\left(\delta_{\mathrm{C}} 78.1\right)$ of glucuronic acid, H-1 $\left(\delta_{\mathrm{H}} 5.33\right)$ of xylose with C-3 $\left(\delta_{\mathrm{C}} 85.7\right)$ of glucuronic acid, H-1 $\left(\delta_{\mathrm{H}} 4.81\right)$ of glucuronic acid with $\mathrm{C}-3\left(\delta_{\mathrm{C}} 83.7\right)$ of the aglycone. Similarly, the sugar chain at $\mathrm{C}-28$ was established from the following HMBC correlations: $\mathrm{H}-1\left(\delta_{\mathrm{H}} 6.05\right)$ of apiose with $\mathrm{C}$ $3\left(\delta_{\mathrm{C}} 84.5\right)$ of xylose, H-1 $\left(\delta_{\mathrm{H}} 5.18\right)$ of xylose with C-4 $\left(\delta_{\mathrm{C}}\right.$ 83.1) of rhamnose, H-1 $\left(\delta_{\mathrm{H}} 6.15\right)$ of rhamnose with C-2 $\left(\delta_{\mathrm{C}}\right.$ 75.9) of arabinose, H-1 $\left(\delta_{\mathrm{H}} 6.36\right)$ of arabinose with C-28 $\left(\delta_{\mathrm{C}}\right.$ 176.4) of the aglycone. The same conclusion with regard to the sugar sequence was also drawn from the NOESY experiment. The D-galactose, D-xylose and D-glucuronic acid were determined as $\beta$-configurations based on their ${ }^{3} J_{\mathrm{H} 1-\mathrm{H} 2}$ values $(J=7.5-7.8 \mathrm{~Hz})$, whereas the L-rhamnose was deduced as $\alpha$-configuration from the broad singlet of its anomeric proton and the ${ }^{13} \mathrm{C}-\mathrm{NMR}$ chemical shift values of $\mathrm{C}-3$ and $\mathrm{C}-5 .{ }^{16}$ ) The $\alpha$-anomeric configuration of the L-arabinose $\left({ }^{1} \mathrm{C}_{4}\right.$ config-

Table 1. ${ }^{13} \mathrm{C}-\mathrm{NMR}$ (DEPT) Data of $\mathbf{1}$ and $\mathbf{2}$ in $\mathrm{C}_{5} \mathrm{D}_{5} \mathrm{~N}(125 \mathrm{MHz})$

\begin{tabular}{|c|c|c|c|c|c|c|c|c|}
\hline No. & 1 & 2 & No. & 1 & 2 & No. & 1 & 2 \\
\hline Aglycone & & & 27 & $27.4, \mathrm{CH}_{3}$ & $27.1, \mathrm{CH}_{3}$ & C-28-O-Sugar & & \\
\hline 1 & $44.3, \mathrm{CH}_{2}$ & $44.5, \mathrm{CH}_{2}$ & 28 & $176.4, \mathrm{C}$ & $176.1, \mathrm{C}$ & Ara (Glc) & Ara & Glc \\
\hline 2 & $70.5, \mathrm{CH}^{2}$ & $70.7, \mathrm{CH}^{2}$ & 29 & $33.3, \mathrm{CH}_{3}$ & $33.1, \mathrm{CH}_{3}$ & 1 & $93.8, \mathrm{CH}$ & $94.8, \mathrm{CH}$ \\
\hline 3 & $83.7, \mathrm{CH}$ & $84.1, \mathrm{CH}$ & 30 & $23.8, \mathrm{CH}_{3}$ & $23.6, \mathrm{CH}_{3}$ & 2 & $75.9, \mathrm{CH}$ & $78.3, \mathrm{CH}$ \\
\hline 4 & $42.9, \mathrm{C}$ & $42.6, \mathrm{C}$ & $\mathrm{C}-3$-O-Sugar & & & 3 & $69.8, \mathrm{CH}$ & $78.5, \mathrm{CH}$ \\
\hline 5 & $47.9, \mathrm{CH}$ & $47.8, \mathrm{CH}$ & GlcA & & & 4 & $65.8, \mathrm{CH}$ & $71.2, \mathrm{CH}$ \\
\hline 6 & $18.2, \mathrm{CH}_{2}$ & $17.9, \mathrm{CH}_{2}$ & 1 & $105.5, \mathrm{CH}$ & $105.4, \mathrm{CH}$ & 5 & $62.5, \mathrm{CH}_{2}$ & $78.6, \mathrm{CH}$ \\
\hline 7 & $33.4, \mathrm{CH}_{2}$ & $32.9, \mathrm{CH}_{2}$ & 2 & $78.1, \mathrm{CH}$ & $74.5, \mathrm{CH}$ & 6 & & $62.4, \mathrm{CH}_{2}$ \\
\hline 8 & $40.2, \mathrm{C}$ & $40.1, \mathrm{C}^{2}$ & 3 & $85.7, \mathrm{CH}$ & $86.5, \mathrm{CH}$ & Rha & & \\
\hline 9 & $47.8, \mathrm{CH}$ & $48.5, \mathrm{CH}$ & 4 & $71.6, \mathrm{CH}$ & $71.4, \mathrm{CH}$ & 1 & 101.4, CH & 101.7, CH \\
\hline 10 & $37.2, \mathrm{C}$ & $37.0, \mathrm{C}$ & 5 & 77.1, CH & $76.9, \mathrm{CH}$ & 2 & $71.8, \mathrm{CH}$ & 71.7, CH \\
\hline 11 & $24.1, \mathrm{CH}_{2}$ & $23.9, \mathrm{CH}_{2}$ & 6 & $171.8, \mathrm{C}$ & $172.1, \mathrm{C}$ & 3 & $72.3, \mathrm{CH}$ & $82.4, \mathrm{CH}$ \\
\hline 12 & $123.0, \mathrm{CH}$ & $123.1, \mathrm{CH}$ & Gal & & & 4 & $83.1, \mathrm{CH}$ & $78.7, \mathrm{CH}$ \\
\hline 13 & $144.4, \mathrm{C}$ & $144.2, \mathrm{C}$ & 1 & $105.8, \mathrm{CH}$ & 105.6, CH & 5 & $68.5, \mathrm{CH}$ & $69.1, \mathrm{CH}$ \\
\hline 14 & $42.6, \mathrm{C}$ & $42.1, \mathrm{C}$ & 2 & $74.5, \mathrm{CH}$ & $72.2, \mathrm{CH}$ & 6 & $18.5, \mathrm{CH}_{3}$ & $18.7, \mathrm{CH}_{3}$ \\
\hline 15 & $36.3, \mathrm{CH}_{2}$ & $28.1, \mathrm{CH}_{2}$ & 3 & $75.4, \mathrm{CH}$ & $81.3, \mathrm{CH}$ & $\mathrm{Xyl}$ & & \\
\hline 16 & $74.2, \mathrm{CH}^{2}$ & $23.3, \mathrm{CH}_{2}$ & 4 & $70.6, \mathrm{CH}$ & $69.7, \mathrm{CH}$ & 1 & 106.7, CH & $105.8, \mathrm{CH}$ \\
\hline 17 & $49.9, \mathrm{C}$ & $47.3, \mathrm{C}$ & 5 & $76.5, \mathrm{CH}$ & $76.8, \mathrm{CH}$ & 2 & $74.3, \mathrm{CH}$ & $75.2, \mathrm{CH}$ \\
\hline 18 & $41.3, \mathrm{CH}$ & $41.5, \mathrm{CH}$ & 6 & $61.6, \mathrm{CH}_{2}$ & $61.8, \mathrm{CH}_{2}$ & 3 & $84.5, \mathrm{CH}$ & $78.4, \mathrm{CH}$ \\
\hline 19 & $47.1, \mathrm{CH}_{2}$ & $46.9, \mathrm{CH}_{2}$ & Xyl (Glc) & Xyl & Glc & 4 & $70.1, \mathrm{CH}$ & $70.9, \mathrm{CH}$ \\
\hline 20 & $30.8, \mathrm{C}$ & $30.9, \mathrm{C}$ & 1 & $106.2, \mathrm{CH}$ & $104.7, \mathrm{CH}$ & 5 & $67.8, \mathrm{CH}_{2}$ & $67.4, \mathrm{CH}_{2}$ \\
\hline 21 & $36.2, \mathrm{CH}_{2}$ & $35.7, \mathrm{CH}_{2}$ & 2 & $75.1, \mathrm{CH}$ & $75.4, \mathrm{CH}$ & Api & & \\
\hline 22 & $32.4, \mathrm{CH}_{2}$ & $32.6, \mathrm{CH}_{2}$ & 3 & $78.6, \mathrm{CH}$ & $77.4, \mathrm{CH}$ & 1 & 111.6, CH & $111.8, \mathrm{CH}$ \\
\hline 23 & $65.8, \mathrm{CH}_{2}$ & $65.4, \mathrm{CH}_{2}$ & 4 & $70.8, \mathrm{CH}$ & $70.1, \mathrm{CH}$ & 2 & $77.5, \mathrm{CH}$ & $77.6, \mathrm{CH}$ \\
\hline 24 & $15.3, \mathrm{CH}_{3}$ & $15.1, \mathrm{CH}_{3}$ & 5 & $67.2, \mathrm{CH}_{2}$ & $77.6, \mathrm{CH}$ & 3 & $79.8, \mathrm{C}$ & $79.6, \mathrm{C}$ \\
\hline 25 & $17.9, \mathrm{CH}_{3}$ & $17.6, \mathrm{CH}_{3}$ & 6 & & $61.4, \mathrm{CH}_{2}$ & 4 & 74.6, $\mathrm{CH}_{2}$ & $74.7, \mathrm{CH}_{2}$ \\
\hline 26 & $16.8, \mathrm{CH}_{3}$ & 16.7, $\mathrm{CH}_{3}$ & & & & 5 & 64.6, $\mathrm{CH}_{2}$ & $64.7, \mathrm{CH}_{2}$ \\
\hline
\end{tabular}


Table 2. Selected ${ }^{1} \mathrm{H}-\mathrm{NMR}$ Data of $\mathbf{1}$ and $\mathbf{2}$ in $\mathrm{C}_{5} \mathrm{D}_{5} \mathrm{~N}(500 \mathrm{MHz}, J$ in $\mathrm{Hz})$

\begin{tabular}{|c|c|c|c|c|c|}
\hline No. & 1 & 2 & No. & 1 & 2 \\
\hline \multicolumn{3}{|c|}{ Aglycone } & 4 & 4.12 & 4.24 \\
\hline 2 & 4.81 , br s & 4.79, br s & 5 & $3.67, \mathrm{t}, 10.1$ & 3.89 \\
\hline 3 & $4.38, \mathrm{~d}, 3.2$ & $4.35, \mathrm{~d}, 3.2$ & & 4.27 & \\
\hline 12 & 5.58, br s & $5.52, \mathrm{brs}$ & 6 & & 4.38 \\
\hline \multirow[t]{2}{*}{16} & 5.16 , br s & 3.20 & & & $4.49, \mathrm{dd}, 12,2$ \\
\hline & & 2.86 & $\mathrm{C}-28-\mathrm{C}$ & -Sugar & \\
\hline 18 & $3.48, \mathrm{dd}, 14.0,3.5$ & $3.34, \mathrm{dd}, 14.0,4.0$ & & Ara & Glc \\
\hline \multirow[t]{2}{*}{19} & $1.38, \mathrm{dd}, 13.5,3.8$ & 1.82 & 1 & $6.36, \mathrm{~d}, 2.8$ & $6.22, \mathrm{~d}, 7.5$ \\
\hline & $2.76, \mathrm{t}, 13.5$ & 1.12 & 2 & 4.65 & 4.26 \\
\hline \multirow[t]{2}{*}{23} & $3.72, \mathrm{~d}, 11.0$ & $3.71, \mathrm{~d}, 11.0$ & 3 & 3.92 & 4.29 \\
\hline & $4.39, \mathrm{~d}, 11.0$ & $4.36, \mathrm{~d}, 11.0$ & 4 & 4.28 & 4.27 \\
\hline 24 & $1.39, \mathrm{~s}$ & $1.39, \mathrm{~s}$ & 5 & 4.22 & 3.96 \\
\hline 25 & $1.58, \mathrm{~s}$ & $1.57, \mathrm{~s}$ & & 4.41 & \\
\hline 26 & $1.18, \mathrm{~s}$ & $1.17, \mathrm{~s}$ & 6 & & 4.32 \\
\hline 27 & $1.76, \mathrm{~s}$ & $1.28, \mathrm{~s}$ & & & $4.38, \mathrm{dd}, 12,2$ \\
\hline 29 & $0.93, \mathrm{~s}$ & $0.93, \mathrm{~s}$ & Rha & & \\
\hline 30 & $1.06, \mathrm{~s}$ & $1.05, \mathrm{~s}$ & 1 & 6.15, br s & 6.18, brs \\
\hline \multicolumn{2}{|c|}{$\mathrm{C}-3-O$-Sugar } & & 2 & 4.85 & 4.92 \\
\hline \multicolumn{2}{|c|}{ GlcA } & & 3 & 4.12 & 4.45 \\
\hline 1 & $4.81, \mathrm{~d}, 7.5$ & $4.78, d, 7.6$ & 4 & 4.23 & 4.29 \\
\hline 2 & 4.35 & 3.88 & 5 & 4.38 & 4.35 \\
\hline 3 & 4.28 & 4.25 & 6 & $1.75, \mathrm{~d}, 6.1$ & $1.78, \mathrm{~d}, 6.0$ \\
\hline 4 & 4.45 & 4.42 & Xyl & & \\
\hline 5 & 4.52 & 4.50 & 1 & $5.18, \mathrm{~d}, 7.8$ & $5.28, \mathrm{~d}, 7.8$ \\
\hline \multicolumn{2}{|c|}{ Gal } & & 2 & 3.98 & 4.03 \\
\hline 1 & $5.57, \mathrm{~d}, 7.6$ & $5.51, \mathrm{~d}, 7.8$ & 3 & 4.09 & 3.91 \\
\hline 2 & 4.46 & 4.48 & 4 & 4.18 & 4.16 \\
\hline 3 & 4.12 & 4.21 & 5 & 3.52 & 3.50 \\
\hline 4 & $4.56, \mathrm{~d}, 3.1$ & $4.50, \mathrm{~d}, 3.0$ & & $4.21, \mathrm{~d}, 7.8$ & $4.22, \mathrm{t}, 7.8$ \\
\hline 5 & 4.01 & 4.02 & Api & & \\
\hline \multirow[t]{3}{*}{6} & 4.30 & 4.28 & 1 & $6.05, \mathrm{~d}, 4.8$ & $6.07, \mathrm{~d}, 5.0$ \\
\hline & 4.52 & 4.51 & 2 & $4.76, \mathrm{~d}, 4.5$ & $4.77, \mathrm{~d}, 4.5$ \\
\hline & Xyl & Glc & 4 & $4.03, \mathrm{~d}, 11.0$ & $4.02, \mathrm{~d}, 11.0$ \\
\hline 1 & $5.33, \mathrm{~d}, 7.5$ & $5.41, \mathrm{~d}, 7.7$ & & $4.05, \mathrm{~d}, 11.0$ & $4.05, \mathrm{~d}, 11.0$ \\
\hline 2 & 3.94 & 4.02 & 5 & $4.26, \mathrm{~d}, 9.5$ & $4.19, \mathrm{~d}, 9.5$ \\
\hline 3 & 4.11 & 4.17 & & $4.65, \mathrm{~d}, 9.5$ & $4.57, \mathrm{~d}, 9.5$ \\
\hline
\end{tabular}

GlcA $=\beta$-D-glucuronopyranosyl, Glc $=\beta$-D-glucopyranosyl, Ara $=\alpha$-L-arabinopyranosyl, Gal $=\beta$-D-galactopyranosyl, Api $=\beta$-D-apifuranosyl, $\mathrm{Rha}=\alpha$-L-rhamnopyranosyl, $\mathrm{Xyl}=\beta$-D-xylopyranosyl

uration) was determined by its ${ }^{3} J_{\mathrm{H} 1-\mathrm{H} 2}(2.8 \mathrm{~Hz})$ and $J_{\mathrm{C} 1-\mathrm{H} 1}$ $(172 \mathrm{~Hz})$ value. $^{17)}$ The $\beta$-anomeric configuration of the $\mathrm{D}$ apiose was determined by the comparison of the ${ }^{13} \mathrm{C}$-NMR data for 1 with those for $\alpha$ and $\beta$-D-apiofuranosides, and the ${ }^{3} J_{\mathrm{H} 1-\mathrm{H}_{2}}$ value of the apiose was similar to the reported data of $\beta$-D-apiofuranoside. ${ }^{18}$ ) Based on the above evidence, the structure of 1 was determined to be $3-O-\beta$-D-galactopyranosyl- $(1 \rightarrow 2)$-[ $\beta$-D-xylopyranosyl- $(1 \rightarrow 3)]-\beta$-D-glucuronopyranosyl-2 $\beta, 3 \beta, 16 \alpha, 23$-tetrahydroxyolean-12-en-28-oic acid 28 - $O$ - $\beta$-D-apiofuranosyl-( $1 \rightarrow 3)$ - $\beta$-D-xylopyranosyl- $(1 \rightarrow 4)$ $\alpha$-L-rhamnopyranosyl-( $1 \rightarrow 2)$ - $\alpha$-L-arabinopyranosyl ester, and called brachyposide A (Fig. 1).

Compound $\mathbf{2}$ was obtained as a white amorphous powder with the molecular formula $\mathrm{C}_{70} \mathrm{H}_{112} \mathrm{O}_{38}$, as determined from the data of the positive (HR)-FAB-MS ( $\mathrm{m} / \mathrm{z} \quad 1561.6873$ $[\mathrm{M}+\mathrm{H}]^{+}$, Calcd for $\left.\mathrm{C}_{70} \mathrm{H}_{113} \mathrm{O}_{38}, 1561.6910\right),{ }^{13} \mathrm{C}-\mathrm{NMR}(70$ carbon signals), and various DEPT spectra. The NMR and DEPT spectra of the aglycone $\mathbf{2}$ were almost similar to those of 1 , apart from the change of the oxymethine $\left(\delta_{\mathrm{H}} 5.16\right.$ and $\left.\delta_{\mathrm{C}} 74.2\right)$ in 1 to methene $\left(\delta_{\mathrm{H}} 2.86,3.20\right.$ and $\left.\delta_{\mathrm{C}} 23.3\right)$ in $\mathbf{2}$, suggesting the hydroxyl group at C-16 in $\mathbf{1}$ was absent in the aglycone 2 . Thus, the aglycone of $\mathbf{2}$ was identified as $2 \beta, 3 \beta$,23-trihydroxyolean-12-en-28-oic acid (bayogenin). ${ }^{19}$ )
Secondly, the presence of seven sugars in $\mathbf{2}$ was apparent from the seven anomeric proton signals at $\delta_{\mathrm{H}} 4.78$ (d, $J=7.6 \mathrm{~Hz}), 5.51(\mathrm{~d}, J=7.8 \mathrm{~Hz}), 5.41(\mathrm{~d}, J=7.7 \mathrm{~Hz}), 6.22(\mathrm{~d}$, $J=7.5 \mathrm{~Hz}$ ), 6.18 (br s), $5.28(\mathrm{~d}, J=7.8 \mathrm{~Hz})$ and $6.07(\mathrm{~d}$, $J=5.0 \mathrm{~Hz}$ ), which correlated with the corresponding carbon signals at $\delta_{\mathrm{C}} 105.4,105.6,104.7,94.8,101.7,105.8$ and 111.8, respectively. Acid hydrolysis of 2 gave D-glucuronic acid, D-glucose, D-galactose, D-xylose, L-rhamnose and Dapiose in the ratio of $1: 2: 1: 1: 1: 1$ as component sugars, which were identified by TLC and GC analysis after derivatization. ${ }^{15)}$ The assignments of all protons and carbon signals of the respective sugar components and the sequence of the oligosaccharide chain were also determined by DEPT, ${ }^{1} \mathrm{H}-{ }^{1} \mathrm{H}$ COSY, HMBC and NOESY spectra of 2 . The $\beta$-anomeric configurations of both D-glucoses were evident from the large ${ }^{3} J_{\mathrm{H} 1-\mathrm{H} 2}(J=7.5,7.7 \mathrm{~Hz})$. The anomeric configurations of the other sugar units were identical to the corresponding ones in compound $\mathbf{1}$. Thus, the structure of $\mathbf{2}$ was determined to be 3 - $O$ - $\beta$-D-glucopyranosyl- $(1 \rightarrow 3)-\beta$-D-galactopyranosyl$(1 \rightarrow 3)$ - $\beta$-D-glucuronopyranosyl- $2 \beta, 3 \beta, 23$-trihydroxyolean12 -en-28-oic acid $28-O$ - $\beta$-D-xylopyranosyl- $(1 \rightarrow 4)$ - $[\beta$-D-apiofuranosyl- $(1 \rightarrow 3)]-\alpha$-L-rhamnopyranosyl- $(1 \rightarrow 2)-\beta$-D-glucopyranosyl ester, and termed brachyposide B (Fig. 1).

\section{Experimental}

General Procedures Melting points were determined on X-4 digital micro-melting point apparatus and were uncorrected. Optical rotations were measured with a Perkin-Elmer 341 digital polarimeter. IR spectra were recorded with $\mathrm{KBr}$ pellets on a Perkin-Elmer 577 spectrometer. GC analysis was performed with a Hewlett Packard 6890 Series gas chromatograph equipped with an $\mathrm{H}_{2}$ flame ionization detector. The FAB-MS were recorded on a VG Autospec 3000 mass spectrometer, and the NMR spectra were recorded with a Bruker AMX-500 $\left(500 \mathrm{MHz}\right.$ for ${ }^{1} \mathrm{H}-\mathrm{NMR}$ and $125 \mathrm{MHz}$ for ${ }^{13} \mathrm{C}$-NMR). Chemical shifts were given in $\delta(\mathrm{ppm})$ with tetramethyl silane (TMS) as an internal standard and coupling constants $(J)$ were reported in Hertz $(\mathrm{Hz})$. Column chromatography was performed with Silica-gel $\mathrm{H}$ (Qingdao Haiyang Chemical Plant, P. R. China), Diaion HP-20 (Mitsubishi Chemical, Japan), Sephadex LH-20 (Pharmacia), and macroporous resin D101 (26-60 mesh, Tianjin Haiguang Chemical Company, P. R. China). Thin-layer chromatography (TLC) employed precoated Silica-gel $\mathrm{GF}_{254}$ plates (Qingdao Haiyang Chemical Plant, China) and detection was achieved by $10 \% \mathrm{H}_{2} \mathrm{SO}_{4}-\mathrm{EtOH}$ for saponins, and aniline-phthalate reagents for sugars.

Plant Material The stem bark of A. brachypus was collected in August of 2007 from Qingyang of Gansu Province, P. R. China, and identified by Prof. Xiao-qiang Guo, Department of Life-Sciences, Longdong University, P. R. China. A voucher specimen (10732) was deposited in the Herbarium of the Department of Life-Sciences, Longdong University.

Extraction and Isolation The air-dried and pulverized stem bark of $A$. brachypus $(30.0 \mathrm{~kg}$ ) was extracted three times with $75 \%$ aqueous $\mathrm{EtOH}$ $(151 \times 7 \mathrm{~d}$, each time) at room temperature, and then the extracts were combined and concentrated under reduced pressure at $60^{\circ} \mathrm{C}$ to give $1460 \mathrm{~g}$ of brown viscous residue. The residue was disolved in $\mathrm{MeOH}$ (1.51) and precipitated in acetone (31). The dry precipitate was suspended in $\mathrm{H}_{2} \mathrm{O}$, and further extracted with $n-\mathrm{BuOH}$ to retain the saponins which have less than nine sugar units. ${ }^{20)}$ The $n-\mathrm{BuOH}$-soluble fraction $(156 \mathrm{~g}$ ) was subjected to column chromatography by a combination of D101 macroporous resin, eluted gradiently with $\mathrm{H}_{2} \mathrm{O}$, EtOH $(10 \rightarrow 95 \%)$ to give five fractions (Fr. A-E). Fraction A $(22.3 \mathrm{~g})$ was subjected to a silica gel column with a $\mathrm{CHCl}_{3}-\mathrm{MeOH}$ gradient system $(1: 0 \rightarrow 0: 1)$, affording 8 subfractions. Subfractions $3(1.1 \mathrm{~g})$ and $7(1.1 \mathrm{~g})$ were respectively purified by repeated octadecyl silane (ODS) column chromatography $\left(\mathrm{MeOH}-\mathrm{H}_{2} \mathrm{O}\right)$ to afford compounds $4(39.4 \mathrm{mg})$ and 3 $(16.4 \mathrm{mg})$. Fraction C (17.5 g) was separated on Sephadex LH-20 column with $\mathrm{MeOH}$, and further recrystallized with $\mathrm{MeOH}$ to provide compounds 5 $(18.1 \mathrm{mg})$ and $\mathbf{6}(22.4 \mathrm{mg})$. Fraction E $(14.7 \mathrm{~g})$ was separated on Sephadex LH-20 column with $\mathrm{MeOH}$, and further purified on ODS column with $\mathrm{MeOH}-\mathrm{H}_{2} \mathrm{O}$ to provide compounds $\mathbf{1}(10.8 \mathrm{mg})$ and $\mathbf{2}(13.2 \mathrm{mg})$.

Brachyposide A (1): White amorphous powder. $[\alpha]_{\mathrm{D}}^{20}-36.5^{\circ}(c=0.22$, $\mathrm{MeOH})$. IR (KBr) $v_{\max } \mathrm{cm}^{-1}: 3418,2937,1730,1648,1422,1074 .{ }^{1} \mathrm{H}-\mathrm{NMR}$ 
(pyridine- $d_{5}, 500 \mathrm{MHz}$ ) and ${ }^{13} \mathrm{C}-\mathrm{NMR}$ (pyridine- $d_{5}, 125 \mathrm{MHz}$ ): see Tables 1 and 2. (HR)-FAB-MS (positive) $m / z: 1517.6621[\mathrm{M}+\mathrm{H}]^{+}$(Calcd for $\left.\mathrm{C}_{68} \mathrm{H}_{109} \mathrm{O}_{37}, 1517.6647\right)$.

Brachyposide $\mathrm{B}(2)$ : White amorphous powder. $[\alpha]_{\mathrm{D}}^{20}-18.6^{\circ}(c=0.18$, $\mathrm{MeOH})$. IR (KBr) $v_{\max } \mathrm{cm}^{-1}: 3422,2938,1727,1652,1423,1072 .{ }^{1} \mathrm{H}-\mathrm{NMR}$ (pyridine- $d_{5}, 500 \mathrm{MHz}$ ) and ${ }^{13} \mathrm{C}-\mathrm{NMR}$ (pyridine- $d_{5}, 125 \mathrm{MHz}$ ): see Tables 1 and 2. (HR)-FAB-MS (positive) $m / z: 1561.6873[\mathrm{M}+\mathrm{H}]^{+}$(Calcd for $\left.\mathrm{C}_{70} \mathrm{H}_{113} \mathrm{O}_{38}, 1561.6910\right)$.

Acid Hydrolysis of Compounds 1 and 2 and Determination of the Absolute Configuration of the Monosaccharide A solution of compounds 1 or $2(5.0 \mathrm{mg})$ in $2 \mathrm{~mol} / 1 \mathrm{HCl}$-dioxane $(1: 1,1 \mathrm{ml})$ was refluxed in a water bath at $90^{\circ} \mathrm{C}$ for $2 \mathrm{~h}$. After dioxane was removed, the solution was extracted with EtOAc $(1 \mathrm{ml} \times 3)$. The aqueous layer was neutralized by passing through an Amberlite MB-3 resin column eluted with $\mathrm{H}_{2} \mathrm{O}$, then concentrated and dried to furnish a monosaccharide residue. Then, the sugars were detected by TLC analysis $\left[\mathrm{CHCl}_{3}-\mathrm{CH}_{3} \mathrm{OH}-\mathrm{H}_{2} \mathrm{O}-\mathrm{HOAc}(15: 6: 2: 3)\right.$, detection solution: aniline-phthalic acid] against the standard samples. The residue was dissolved in pyridine $(0.2 \mathrm{ml})$, and then a pyridine solution $(0.3 \mathrm{ml})$ of L-cysteine methyl ester hydrochloride $(5 \mathrm{mg})$ was added to the solution. The mixture was kept at $60^{\circ} \mathrm{C}$ for $1.5 \mathrm{~h}$, dried in vacuo, and trimethylsilylated with hexamethyl-disilazane-trimethylchlorosilane (HMDSTMCS) $(0.1 \mathrm{ml})$ at $60^{\circ} \mathrm{C}$ for $1 \mathrm{~h}$. After being partitioned between $n$-hexane $(0.5 \mathrm{ml})$ and $\mathrm{H}_{2} \mathrm{O}(0.5 \mathrm{ml})$, the $n$-hexane extract was concentrated and analyzed by GC under the following conditions: HP-5 MS fused silica capillary column $(30 \mathrm{~m} \times 0.25 \mathrm{~mm}$, film thickness $0.25 \mu \mathrm{m})$, column temperature at $230^{\circ} \mathrm{C}$, injection temperature at $250^{\circ} \mathrm{C}, \mathrm{N}_{2}$ as carrier gas. The sugars were confirmed by comparison of the retention times of their derivatives with standard samples [retention time, D-glucuronic acid (20.1 min), D-glucose (24.7 $\mathrm{min})$, D-galactose $(26.6 \mathrm{~min}), \quad \mathrm{D}$-xylose $(17.5 \mathrm{~min}), \quad$ L-rhamnose $(19.3 \mathrm{~min})$, L-arabinose $(18.8 \mathrm{~min})$ and $\mathrm{D}$-apiose $(12.8 \mathrm{~min})]$. The presence of D-glucuronic acid, D-galactose, D-xylose, L-arabinose, L-rhamnose and Dapiose in 1, D-glucuronic acid, D-galactose, D-xylose, D-glucose, L-rhamnose and D-apiose in $\mathbf{2}$ were detected.

Acknowledgements This work was financially supported by the Support Program for Longyuan Scientific and Technical Innovation Talented Person of Gansu Province and the Scientific Research Project of Longdong University (XYZK0802) of China.

\section{References}

1) Delectis Florae Reipublicae Popularis Sinicae, Agendae Academiae Sinicae Edita, "Florae Reipublicae Popularis Sinicae," Vol. 54, Science Press, Beijing, 1980, pp. 104-106.

2) Ni N., Liu X. Q., Chin. Tradit. Herb. Drugs, 37, 1895-1900 (2006).

3) Nishibe S., Kinoshita H., Takeda H., Okano G., Chem. Pharm. Bull., 38, 1763-1765 (1990).

4) Chang S. Y., Yook C. S., Nohara T., Chem. Pharm. Bull., 46, 163165 (1998).

5) Yook C. S., Kim I. H., Hahn D. R., Nohara T., Chang S. Y., Phytochemistry, 49, 839-843 (1998).

6) Chang S. Y., Yook C. S., Nohara T., Phytochemistry, 50, 1369-1374 (1999).

7) Wang Z. L., Liu L. D., Tian G. W., Shen J. H., Biodiv. Sci., 5, 251256 (1997).

8) Yi J. M., Kim M. S., Seo S. W., Lee K. N., Yook C. S., Kim H. M., Clin. Chim. Acta, 32, 163-168 (2001).

9) Wei P., Yu G. M., Chin. Tradit. Herb. Drugs, 20, 152-154 (1989).

10) Zhong H. M., Chen C. X., Tian X., Chui Y. X., Chen Y. Z., Chin. Chem. Lett., 10, 391-394 (1999).

11) Miyakoshi M., Shirasuna K., Hirai Y., Shingu K., Isoda S., Shoji J., Ida Y., Shimizu T., J. Nat. Prod., 62, 445-448 (1999).

12) Tommasi N. D., Autore G., Bellino A., Pinto A., Pizza C., Sorrentino R., Venturella P., J. Nat. Prod., 63, 308-314 (2000).

13) Shao C. J., Kasai R., Xu J. D., Tanaka O., Chem. Pharm. Bull., 37, $42-45$ (1989).

14) Asada Y., Ueoka T., Furuyua T., Chem. Pharm. Bull., 37, 2139-2146 (1989).

15) Zhao J., Nakamura N., Hattori M., Yang X. W., Komatsu K., Qiu M. H., Chem. Pharm. Bull., 52, 230-237 (2004).

16) Sang S., Lao A., Wang H., Chen, Z., J. Nat. Prod., 62, 1028-1029 (1999).

17) Ishii H., Kitagawa I., Matsushita K., Shirakawa K., Tori K., Tozyo T., Yoshikawa M., Yoshimura Y., Tetrahedron Lett., 22, 1529-1532 (1981).

18) Su Y. F., Koike K., Guo D., Satou T., Liu J. S., Zheng J. H., Nikaido T., Tetrahedron, 57, 6721-6726 (2001).

19) Abdulmagid A. M., Laurence V. N., Isabelle R., Dominique H., Christian M., Catherine L., Phytochemistry, 67, 2096-2102 (2006).

20) Wang M. K., Wu F. E., Chen Y. Z., Phytochemistry, 44, 333-335 (1997). 